\title{
Assessment of Lost Of Agricultural Farmland Using Remote Sensing Techniques in Gudu Local Government Area of Sokoto State
}

\author{
Muhammad, Mansur Aliyu
}

\author{
Department of Geography \\ Shehu Shagari College of Education, Sokoto-Nigeria
}

\section{Doi:10.5901/jesr.2013.v3n8p145}

\begin{abstract}
Assessment of loss of Agricultural farmland using Remote Sensing Techniques is an area of significance that has been attracting swelling attention. This paper is an attempt to assess the changes in Agricultural farmland in Gudu town of Sokoto State over a 13 year period. The study made use of LandSat imageries of 1986 and 1999. The images were classified using Maximum Likelihood Classification method after which the land use land cover Maps produced for the periods are overlaid. The results show that loss of Agricultural farmland to bare soil constituted the most extensive type of land use/land cover in the study area. The increasing population and economic activities were noted to be putting pressure on the available land. This paper highlights the importance of Remote Sensing and GIS Techniques in apprehending the situation in order to save the environment for our future generation in Gudu Local Government area of Sokoto State and the nation as a whole.
\end{abstract}

Keywords:Remote Sensing, Agricultural Farmland, LandSat Images, Techniques, Maximum Likelihood

\section{Introduction}

Land use is only one such aspect, but knowledge about the land cover/land use has become increasingly important as the nations plans to overcome the problems of haphazard, uncontrolled development, deteriorating environmental quality, loss of prime agricultural lands, and destruction of important wetlands.

Increase in population, destruction of environmental resources, environmental pollution, as well as human activities have been recognized as a major force shaping the biosphere those are the various issues threatening the environment today Vernon, (2002).

Land use data are needed in the analysis of environmental processes and problems that must be understood if living conditions and standards are to be improved or maintained at current levels UN-habitat, (2003).

Globally, urban centres over a half century ago have continued to witness unprecedented growth in its population in most developing countries. This growth is premised on the perceived improvement in living conditions and the environment Kombe and Kreibich, (2000), thereby triggering high level migration usually one way from the rural areas to the urban areas. This phenomenon comes with high level population increase in the urban areas as well as consistent decline in economic opportunities in rural areas (Gardner, 2001; UN-Habitat, 2003).

Thematic Committee (2001) opines that in Nigeria the growth and complexity of human settlements and in particular the process of urbanization has been phenomenal. 1950, the percentage of the total Nigerian population living in urban centres was less than 15 per cent; by 1975 , this proportion had risen to some 23.4 per cent. By year 2000, the proportion had gone up to more than 43.5 per cent and it is been projected to be more than 50 per cent by the year 2010

The conversion of agricultural farmland land to urban use, settlement expansion desert 
encroachment, wetland in the rural environment is inevitable for many developing countries. However, there is a need to minimize the impacts of agricultural land loss through sustainable land allocation: that is, to create a balance between land development and conservation, so that the needs of both present and future generations can be met.

Sokoto State is one of the states in Nigeria that has been faced with environmental threat for years, it should be noted however that, Gudu is one of the area in the state that is faced with challenges of losing potentialities in farmland, hence the need for geospatial technologies such as Remote Sensing in enhancing monitoring and management efforts for agricultural farmland in the study area.

\section{Methods and Procedures}

To study land use change dynamics at a regional level with a comparable level of confidence, landuse and socio-economic data of the study area were needed. Data collection and ground truthing necessitated visits to Gudu town.

\section{Data Sourcing, Acquisations and Processing}

The Landsat TM data covering Sokoto State for 1986 and Landsat ETM data for 1999 were obtain from the Sokoto State office of the Surveyor General, to add to this data other relevant documents were also obtained from the Sokoto State Ministry for Agriculture, Ministry for Environment and Ministry for Forestry and Animal Health respectively. However, the paper entailed gathering relevant information to the assessment of loss of Agricultural Farmland in Gudu Town, the georeferencing and sub-mapping of the image imageries used as data for the purpose of the paper was carried out using ILWIS 3.3 Software, the figure 1 below summarized the work flow process adopted in carrying out the paper

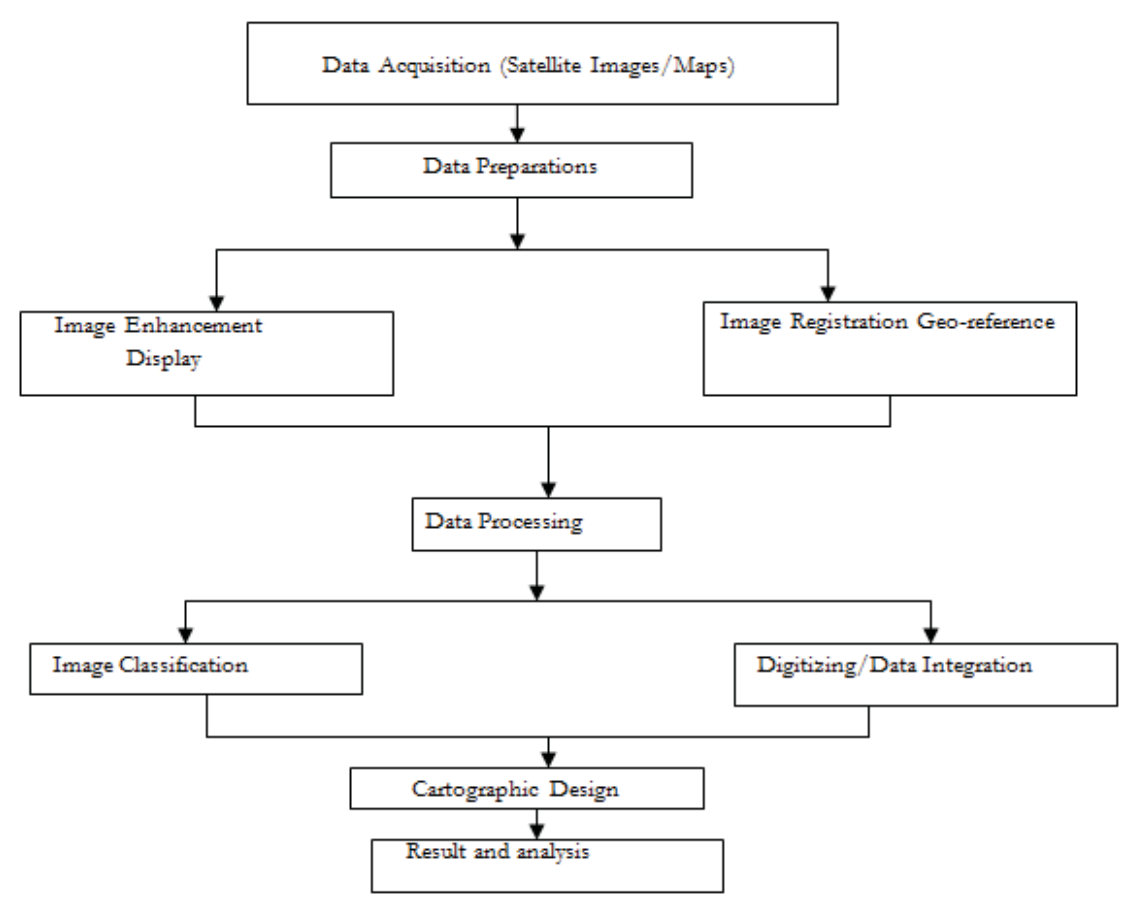

Figure 1: Work flow diagram. 


\section{Image Sub-Mapping and Image Classification}

During the image sub-mapping the study area was sub-mapped and enhanced using the contrast stretching techniques of the global contrast enhancement method, the spectral band were combined to obtain a colour composite by formation of bands 4, 3 and 2 for both 1986 and 1999 respectively, the result of the colour composite is shown below in figure 2 and 3 respectively. However, image classification is a conventional change detection method which provides an avenue to create series of Land cover maps, and in order to produce land use land cover maps after classification that will the various changes that occur due to loss of Agricultural farmland in the study area, the satellite imageries of Landsat TM of 1986 and Landsat ETM of 1999 was classified using maximum likelihood classification algorithm, and the results are shown in figure 4 and 5, for the purpose of this paper predefined classes depicting the various land use within the study area was identified thus include: Bare soil, Built up area, Farmland, Vegetation, Wetland and Water bodies.

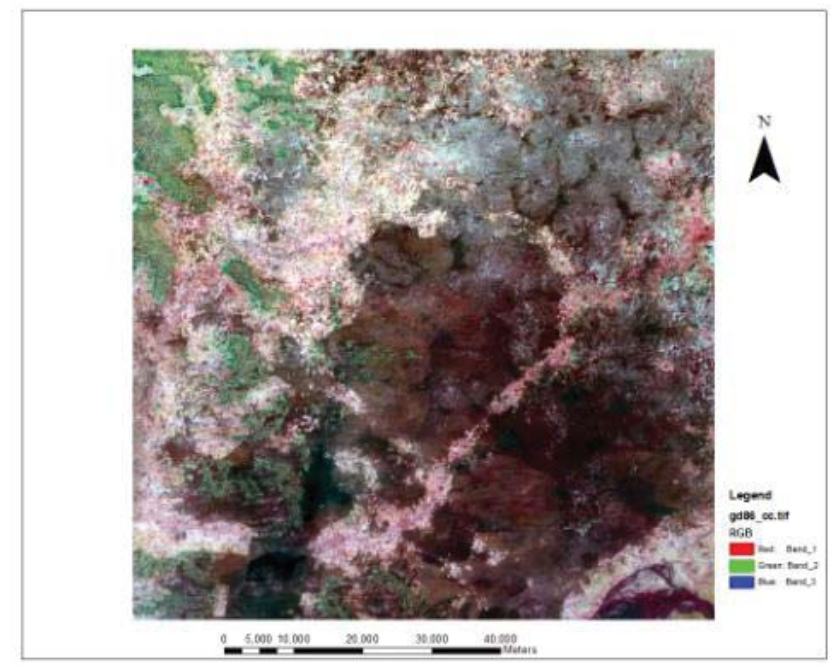

Figure 2: Submap colour composite of the study area of LandSatTM 1986

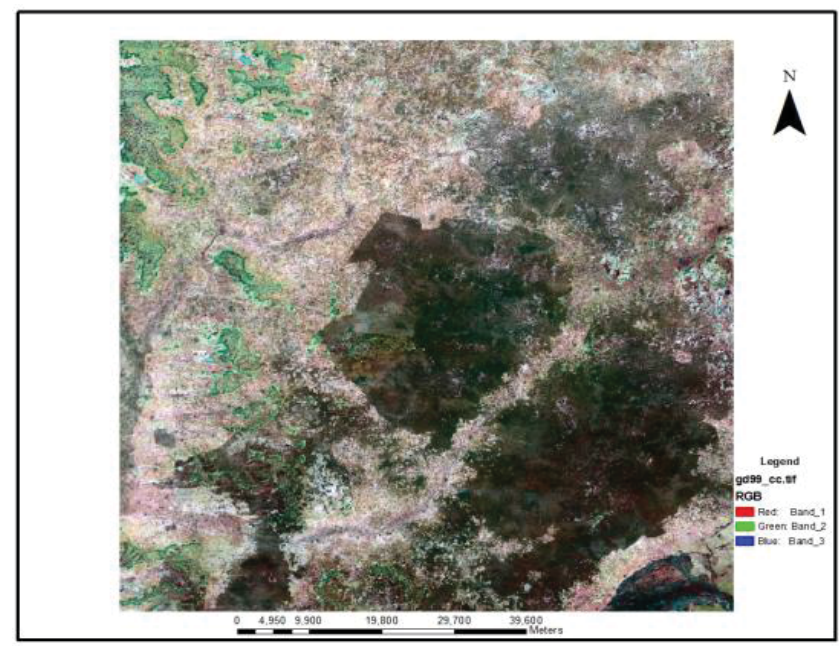

Figure 3: Submap colour composite of the study area of LandSat ETM 1999 


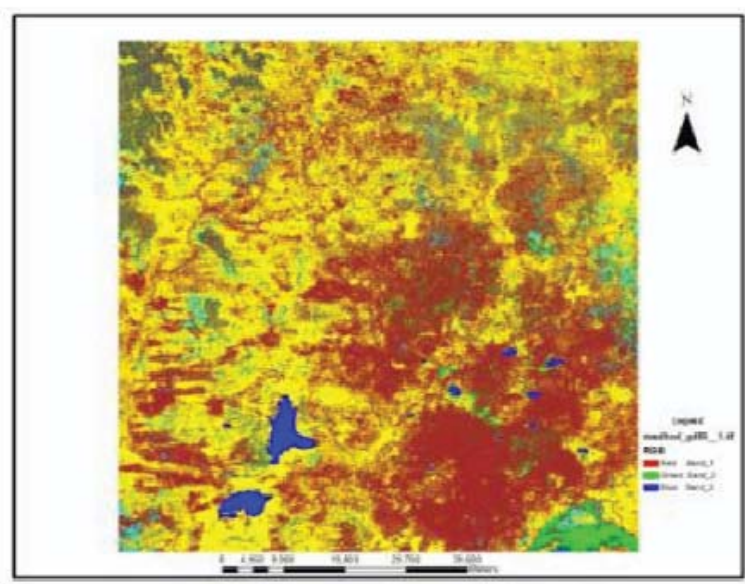

Figure 4: I mage classified of LandSat TM 1986, using maximum likelihood

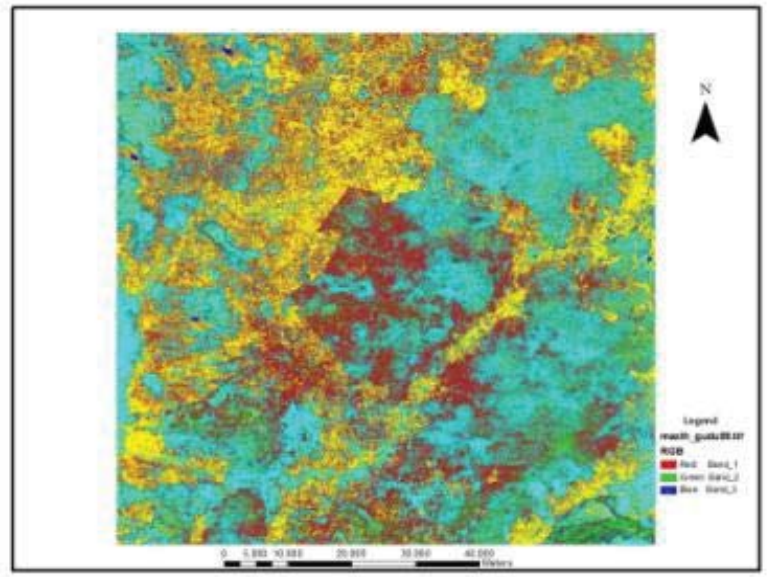

Figure 5: I mage classified of LandSat ETM 1999, using maximum likelihood Map Overlay

One basic way to create or identify spatial relationships is through the process of overlay. Spatial overlay is accomplished by joining and viewing together separates datasets that share all or part of the same area. The results of this combination will give new data set that in no small measure identifies the spatial relationships this will allow the user to view and analysize those portions of the various layers which cover the same place on the earth surface. However, for the purpose of this paper the intersect overlay analysis was carried out in order to analysed the changes that occurs within the study area. 


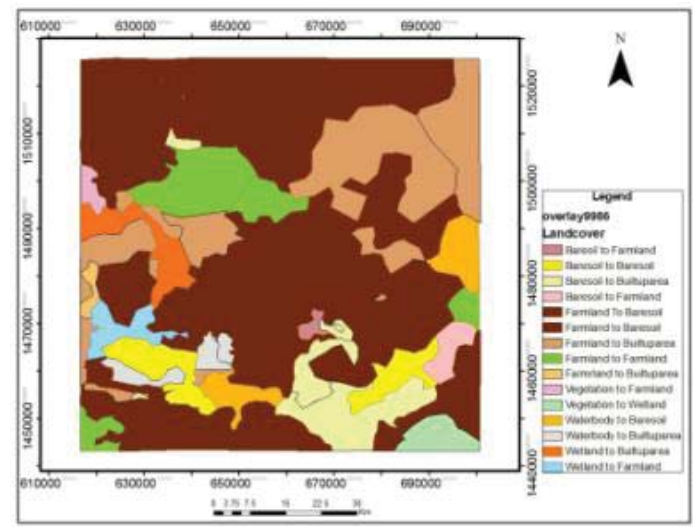

Figure 6: Overlay map between 1986 and 1999 showing changes of Land cover

Table1: Showing change per area and percentage from one class feature to another

\begin{tabular}{|l|c|c|}
\hline \multicolumn{1}{|c|}{ Changes } & Area $\left(\mathrm{Km}^{2}\right)$ & Percentage $(\%)$ \\
\hline Farmland to Built up area & 1108 & 20 \\
\hline Farmland to Bare soil & 3975 & 72 \\
\hline Farmland to Farmland & 437 & 8 \\
\hline Total & 5520 & 100 \\
\hline
\end{tabular}

\section{Reults and Analysis}

The result obtained in the analysis has shown the potentialities of Remote Sensing in assessing the loss of Agricultural farmland. After the two images of the study have been overlaid the result revealed that, Farmland areas covering an area $1108 \mathrm{Km}^{2}$ which accounted for $20 \%$ was lost due to increase of built up in 1999, out of the $29769.3 \mathrm{Km}^{2}$ in 1986 . This attributed to the fact there is increase demand for shelter which is as a result of increase in population in the study area. Similarly, bare soil extent in the Agricultural farmland in the study area as of 1999 has been increase tremendously covering virtually an area of $3975 \mathrm{Km}^{2}$ that accounted for $72 \%$ as indicated in Table 1 and figure 4.6 respectively, out of the initial $29769.3 \mathrm{Km}^{2}$ of agricultural farmland in Gudu. This is unconnected with the fact the action of climate change has already manifested in the area, equally the action of desert encroachment has also prevailed which is as a result of the fact that Gudu is neighbouring Republic of Niger to the North West and there is always the prevalence of trade wind which is associated with dryness encroaching in to the area and this has lead to the loss of agricultural farmland to that extent in Gudu Local Government area.

\section{Conclusion}

The result of this study indicated that, Gudu Local Government area experienced an increase of $72 \%$ in the loss of Agricultural farmland to bare soil between 1986 to 1999 and increase of $20 \%$ to Built up area. Going by this trend it is an illustration that the area is virtually a desert environment and it is a clear indication that from 1999 to date the area might have been seriously lost so many potentialities and may be at risk of food insecurity. From the preceding it can be firmly stated that assessment of loss of agricultural farmland is essential in order to trounce the effect of desertification and food insecurity and above all the consequences of climate change in our environment which will eventually help us to save our environment for our future generation.

Furthermore the output of the various analyses shows that the application of Geoinformation technology is an influential tool for emergent pronouncement support system based on the 
availability of spatially referenced data.

\section{Recommendations}

In rounding up this paper it is important to stated out some recommendations that will help the Sokoto State Government and all stakeholders in this industry in order to undertake necessary measure in controlling the rate at which Agricultural farmland are loss in the State and to protect the menace of affecting our environment in the future. These recommendations are;

1. Establish a land information system for effective monitoring, supervision and control of desert encroachment in the State.

2. There is the need to have a passionate public enlightenment campaign on the dangers associated with human activities such as overgrazing and deforestation which eventually lead loss of agricultural farmland.

3. The need to have an appropriate and ample programme to improve on the reduction of impact of climate change in the area and the State as a whole.

4. There the need to institute policies and convention that will save from harm further loss of agricultural farmland bearing in mind the penalty that may arise.

5. There is the need for versatile usage of land all the time in order to make the farmland fully utilize as this may reduce the rate at which farmland are waste in the study area and the State in general.

6. There is the need for a comprehensive monitoring and assessment of human activities in the area so that to check the level at which these activities impinge on the agricultural farmland.

\section{References}

Gardner, G. (2001). Population increase steadily vital signs 2001, World Watch Institute, W.W Norton and Company, New York., pp 74-75.

Kombe, W.J. and Kreibich, V. (2000). Reconciling informal and formal land management; an agenda for improving tenure security and urban governance in poor countries, Habitat International, 24 (2): 231-240

Thematic Committee, (2001). Sustainable urban development and good governance in Nigeria- Istanbul UN-Habitat (2003). The Challenges of Slums, Global Report on Human Settlements 2000. Earth scan, London.

Vernon, H. (2002). Urbanization in Developing Countries; the World Bank Research Observer, 17 (1): 89 112. 